\title{
Competing Dissolution Pathways and Ligand Passivation-Enhanced Interfacial Stability of Hybrid Perovskites with Liquid Water
}

\author{
Huanhuan Zhou ${ }^{\dagger}$, Jingfan Wang ${ }^{\dagger}$, Mingchao Wang ${ }^{*^{*}}$ and Shangchao Lin ${ }^{\S *}$ \\ ${ }^{\dagger}$ Department of Mechanical Engineering, Materials Science and Engineering Program, FAMU- \\ FSU College of Engineering, Florida State University, Tallahassee, Florida 32310, USA \\ Department of Materials Science and Engineering, Monash University, Clayton, Victoria 3800, \\ Australia \\ ${ }^{\S}$ Institute of Engineering Thermophysics, School of Mechanical and Power Engineering, \\ Shanghai Jiao Tong University, Shanghai 200240, China \\ *Corresponding Authors: \\ mingchao.wang@monash.edu (Dr. Mingchao Wang) \\ shangchaolin@sjtu.edu.cn (A/Prof. Shangchao Lin)
}

\section{S1. Development of an Empirical Potential for the Ligand-MAPbI ${ }_{3}$-Water System}

\section{S1.1 Potential Training and Validation for $\mathrm{MAPbI}_{3}$}

The recently developed empirical model potential for hybrid perovskites (MYP0) ${ }^{1}$ has been widely utilized to predict multi-physical (structural and phase diagram, ${ }^{1}$ mechanical, ${ }^{2}$ thermal and vibrational, ${ }^{3,4}$ ionic diffusivity, ${ }^{5}$ nucleation, ${ }^{6}$ and caloric ${ }^{7}$ ) properties of $\mathrm{MAPbI}_{3}$. However, 
the MYP0 potential tends to overestimate the cohesive energy between $\mathrm{MAPbI}_{3}$ and water, ${ }^{8}$ and hence, might underestimate the water contact angle on $\mathrm{MAPbI}_{3},{ }^{9}$ due to the high partial charges assigned. Therefore, Caddeo et al. developed the MYP1 potential to modulate $\mathrm{MAPbI}_{3}-\mathrm{water}$ interactions by rescaling the partial charges by $0.62 .{ }^{8,10}$ Moreover, the non-integer partial charges assigned to $\mathrm{I}, \mathrm{Pb}$ and MA ions in MYP, ${ }^{1} \mathrm{MYP} 1,{ }^{8}$ and the new potential by Handley et $a l{ }^{11}$ are inconsistent with the conventional integer valence charges assigned to ions (i.e., e for $\mathrm{I}^{-}$, $-2 \mathrm{e}$ for $\mathrm{Pb}^{2+}$, and -e for $\left.\mathrm{MA}^{+}\right){ }^{11}$ Therefore, without carefully-designed charge rescaling, it is challenging to integrate the MYP and the MYP1 potentials with the conventional potentials for organic molecules, such as AMBER ${ }^{12}$ (which is used to model MA ${ }^{+}$in both MYP and MYP1, but with rescaled non-integer partial charges $\left.{ }^{1,8}\right)$, CHARMM $^{13}$ and OPLS-AA. ${ }^{14}$

With the above in mind, we developed a new potential for the $\mathrm{MAPbI}_{3}$-water system based on the functional forms in the MYP potential, ${ }^{1}$ which is referred to as the m-MYP potential here. The m-MYP potential is designed to assign integer partial charges for $\mathrm{I}^{-}, \mathrm{Pb}^{2+}$ and $\mathrm{MA}^{+}$ions, in order to be consistent with the AMBER potential and reflect their natural valence charges. The MYP parameters, except for the partial charges, were used as the initial guesses for training the m-MYP potential. Specifically, we re-trained all the Buckingham potential parameters for the pairwise $\mathrm{Pb}-\mathrm{Pb}, \mathrm{Pb}-\mathrm{I}, \mathrm{I}-\mathrm{I},(\mathrm{Pb}, \mathrm{I})-(\mathrm{C}, \mathrm{N})$ interactions and some Lennard-Jones (LJ) 12-6 potential parameters for the pairwise $(\mathrm{Pb}, \mathrm{I})-\mathrm{H}$ interactions. Other non-bonded LJ, bond stretching, angular bending, and dihedral parameters remain the same as those in the MYP potential. The atomic partial charges were all fixed during the training process, and the original, unscaled AMBER partial charges for the atoms in $\mathrm{MA}^{+}$were used here (see Table S1). A cutoff distance of $10 \AA$ is used for all the pairwise interactions. Structural relaxation and energy minimization (i.e., molecular mechanics, MM, at $0 \mathrm{~K}$ ) are allowed during the training process. 
The m-MYP potential for a pseudo-cubic $\mathrm{MAPbI}_{3}$ crystal is trained in the GULP $5.0^{15}$ package using the DFT-predicted bulk (16.4 GPa, with a weighting factor of 10) and shear (8.7 GPa, with a weighting factor of 10) moduli, ${ }^{16}$ as well as experimental and DFT-predicted unit cell volume

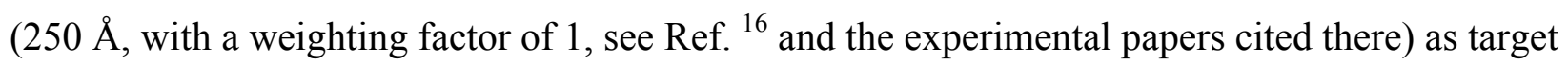
properties. The Voigt-Reuss-Hill (VRH) approximation ${ }^{17}$ is used to calculate the bulk and shear moduli based on the computed elastic constants after energy minimization. The training was carried out using the Newton-Raphson algorithm to minimize the sum of squares between the calculated and the target properties. The final m-MYP potential (see Table S1 for the potential parameters) can reproduce the targeting properties considered here within 5\%.

A comprehensive comparison between major structure and mechanical properties of pseudocubic $\mathrm{MAPbI}_{3}$ calculated using the m-MYP potential and those from DFT calculations ${ }^{16}$ are shown in Table S2. Our focus on the higher temperature pseudo-cubic $\mathrm{MAPbI}_{3}$ phase is reflected from the typical hot and moisture environment that accelerates the surface degradation of $\mathrm{MAPbI}_{3}$. Therefore, it is important to note that the lower temperature phase transition behaviors (from cubic to tetragonal, and then to orthorhombic) and the related structural and physical properties of $\mathrm{MAPbI}_{3}$ are not considered in the training and validation of the current $\mathrm{m}$ MYP. The Young's modulus at $0 \mathrm{~K}$ was calculated using the VRH approximation ${ }^{17}$ after MM in GULP. For comparison, the room-temperature Young's modulus was calculated based on separate MD simulations using the LAMMPS package. ${ }^{18}$ After an energy minimization using the conjugate-gradient method, the NPT ensemble ( 1 bar and $300 \mathrm{~K}$ ) and a timestep of $1 \mathrm{fs}$ were used for MD simulations. The room-temperature Young's modulus of a $3.5 \times 3.5 \times 12.8 \mathrm{~nm}^{3}$ pseudo-cubic $\mathrm{MAPbI}_{3}$ sample was calculated based on the simulated stress-strain curve along the $\mathrm{z}$-axis with a strain rate of $0.02 \mathrm{~ns}^{-1}$. In summary, the m-MYP potential can reproduce the major 
structure and mechanical properties of pseudo-cubic $\mathrm{MAPbI}_{3}$ well after comparing to the $\mathrm{DFT}$ calculations. ${ }^{16}$ The accuracy of m-MYP relies on both the accuracy of the reference properties either predicted by DFT or obtained from existing experiments, in addition to the numerical fitting algorithm to obtain the parameters. It is important to note that m-MYP is parametrized against pseudo-cubic $\mathrm{MAPbI}_{3}$-water interactions. Therefore, cautions should be taken when extending m-MYP towards interactions between $\mathrm{MAPbI}_{3}$ and other solvents or studying phase transitions in $\mathrm{MAPbI}_{3}$. Further extensions and validations of m-MYP or new potential training will be considered in future studies.

\section{S1.2 Potential Validation for Ligand-MAPbI ${ }_{3}$-Water Interactions}

The m-MYP potential developed here is used to model $\mathrm{MAPbI}_{3}$. The $\mathrm{SPC} / \mathrm{E}^{19}$ potential was used here to model water molecules. The $\mathrm{MA}^{+}$-water interactions are described by the sum of the $\mathrm{LJ}$ and Coulombic terms in the AMBER potential. ${ }^{12}$ The LJ parameters of the cross-term $\mathrm{MA}^{+}-$ water interactions are determined using the common Lorentz-Berthelot mixing rule, i.e., $\sigma_{i j}=\left(\sigma_{i i}+\sigma_{j j}\right) / 2$ and $\varepsilon_{i j}=\sqrt{\varepsilon_{i i} \varepsilon_{j j}}$. The rationally-designed $\mathrm{LJ}$ parameters for $\mathrm{Pb}^{20}$ and $\mathrm{I}^{21}$ ions (see Table S1 for details) in explicit solvents are utilized to model ( $\mathrm{Pb}$, I)-water interactions based on the same mixing rule. Similar to $\mathrm{MA}^{+}$cations, the long-chain alkyl ammonium $\left(\mathrm{CH}_{3}\left(\mathrm{CH}_{2}\right)_{n} \mathrm{NH}_{3}{ }^{+}, n=3,7\right)$ cationic ligands are modeled by the AMBER potential. ${ }^{12}$ The atomic partial charges of these ligands (see Figure S1 for values) were determined from quantum chemistry calculations (with geometry optimization) and the electrostatic potential (ESP) population analysis with the Hartree-Fock/6-31G ${ }^{*}$ basis set using the Gaussian 03 package. ${ }^{22}$ This protocol has been commonly used to assign partial charges for the AMBER potential. ${ }^{12}$ The 
particle-particle particle-mesh (PPPM) method ${ }^{23}$ is adopted here to treat long-range Coulombic interactions.

The potential parameters for $\mathrm{MAPbI}_{3}$-water interactions were first validated upon confirming the experimentally observed insolubility of $\mathrm{PbI}_{2}$ crystals in water at $300 \mathrm{~K}$ (see Figure S2). The $\mathrm{PbI}_{2}$ crystal was first constructed and equilibrated in MD simulations under the NPT ensemble ( 1 bar and $300 \mathrm{~K}$ ) using the LAMMPS package. ${ }^{18}$ The face-sharing $\mathrm{PbI}_{6}$ octahedra form the layered $\mathrm{PbI}_{2}$ crystal structure, which is nicely reproduced using the m-MYP potential at $300 \mathrm{~K}$. The crystal structure of $\mathrm{PbI}_{2}$ remains very stable when in contact with water under the NPT ensemble ( 1 bar and $300 \mathrm{~K}$ ) in the MD simulation. As shown in Figure S2, the $\mathrm{PbI}_{2}$ surface exhibits minor structural fluctuation and ionic dissociation after freely exposed to water for $10 \mathrm{~ns}$.

Further validation of the potential parameters for $\mathrm{MAPbI}_{3}$-water interactions was carried out by investigating the adsorption and infiltration energies of a single water molecule interacting with $\mathrm{MAPbI}_{3}$. The initial configurations of the adsorption and the infiltration systems use the same $\mathrm{MAPbI}_{3}$ slab with a simulation box dimension of $4.4 \times 4.4 \times 7.3 \mathrm{~nm}^{3}$ (see Figure S3). As shown in Figure S3a for the adsorption system, a single water molecule was placed above the $\left[\mathrm{PbI}_{2}\right]^{0}$ terminated surface with the water dipole pointing along the z-axis, such that the $\mathrm{O}$ atom is very close to the nearest $\mathrm{Pb}$ atom. On the other hand, as shown in Figure S3b for the infiltration system, a single water molecule was placed below the first layer of $\mathrm{MA}^{+}$cations with the water dipole pointing along the negative z-axis. Note that both configurations were suggested as the low-energy states for $\mathrm{MAPbI}_{3}$-water interactions from DFT calculations. ${ }^{24}$

Both the adsorption and the infiltration systems were relaxed under the $\mathrm{NP}_{x y} \mathrm{~T}$ (at $1 \mathrm{~K}$ and 1 bar controlled along the $x$ and $y$ axes) ensemble for 10 ps of MD simulations using the LAMMPS 
package. This time frame is long enough to allow stress relaxation, and short enough to avoid excessive water diffusion. After subsequent energy minimization, the total potential energies $E_{\text {ads-system }}$ for the adsorption system and $E_{\text {infil-system }}$ for the infiltration system were recorded. The water adsorption energy is evaluated by $E_{a d s}=E_{a d s-s y s t e m}-\left(E_{\text {MAPbI }_{3}}+E_{\text {water }}\right)$, where $E_{M A P b I 3}$ and $E_{\text {water }}$ describe the energies of the pure $\mathrm{MAPbI}_{3}$ slab and the water molecule in the system, respectively. Similarly, the water infiltration energy is evaluated by $E_{\text {infil }}=E_{\text {infli-system }}-\left(E_{\mathrm{MAPbl}_{3}}+E_{\text {water }}\right)$, where $E_{M A P b I 3}$ and $E_{\text {water }}$ describe the energies of the pure $\mathrm{MAPbI}_{3}$ slab and the water molecule in the infiltration system, respectively. Finally, we found that $E_{\text {ads }}=0.80 \mathrm{eV}$ and $E_{\text {infil }}=0.47 \mathrm{eV}$, which are close to the DFT results reported by Caddeo et $a l^{8}$ (see Table $\mathbf{S 3}$ for comparison).

A closer look at the equilibrated near-surface region in the water adsorption and infiltration systems reveals interesting structural features. For water adsorption, the water molecule is stably anchored to the $\left[\mathrm{PbI}_{2}\right]^{0}$ surface due to the strong Coulombic attractive force between the $\mathrm{O}$ atom and the nearest $\mathrm{Pb}$ atom on the surface (see Figure S3a, $\mathbf{c}$ and $\mathbf{d}$ ). For water infiltration, the presence of the water molecule results in a considerable displacement of the nearest $\mathrm{MA}^{+}$cation due to (i) the excluded volume occupied by water, and (ii) the strong dipolar attractions between water and the $\mathrm{NH}_{3}{ }^{+}$group in the $\mathrm{MA}^{+}$cation (see Figure $\mathbf{S 3 b}$, e and f). Finally, we validated the potential parameters for $\mathrm{MAPbI}_{3}$-water interactions from the water wetting behavior on the $[\mathrm{MAI}]^{0}$ and $\left[\mathrm{PbI}_{2}\right]^{0}$ surfaces of $\mathrm{MAPbI}_{3}$. The water wetting behavior was quantified based on water contact angle calculations, in comparison with existing experimental data, ${ }^{25}$ which will be discussed in details in the next section and in Table S3. 
(a) butylammonium (C4)
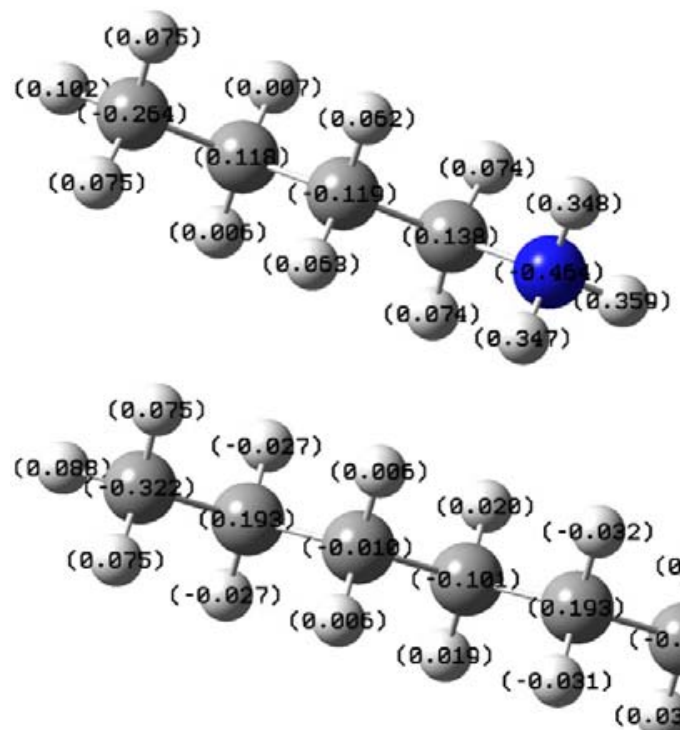

(b) octylammonium (C8) (c) neopentylammonium (B5)
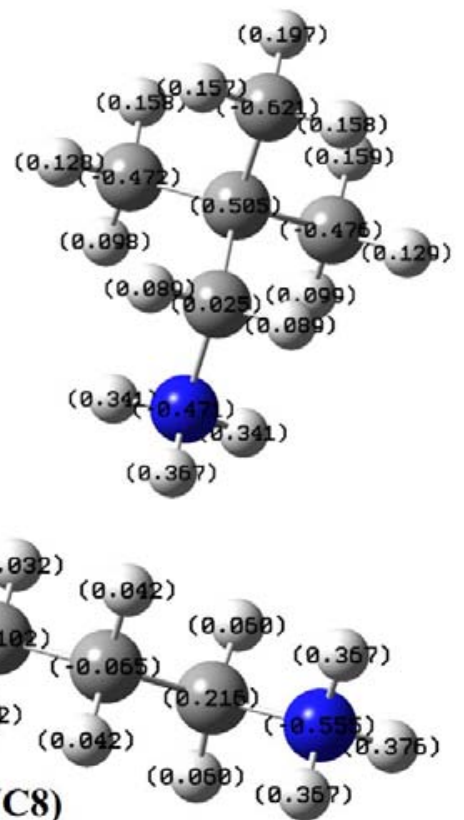

Figure S1. Atomic structures and partial charges of three organic ligands, including linear (a) butylammonium $\mathrm{C}^{+}\left(\mathrm{CH}_{3}\left(\mathrm{CH}_{2}\right)_{3} \mathrm{NH}_{3}{ }^{+}\right)$and (b) octylammonium $\mathrm{C}^{+}\left(\mathrm{CH}_{3}\left(\mathrm{CH}_{2}\right)_{7} \mathrm{NH}_{3}{ }^{+}\right)$, as well as branched (c) neopentylammonium $\mathrm{B}^{+}\left(\left(\mathrm{CH}_{3}\right)_{3} \mathrm{CCH}_{2} \mathrm{NH}_{3}{ }^{+}\right)$. The partial charges for any isotropic atoms are obtained through averaging the individually calculated partial charges. Color code: $\mathrm{C}$ - grey; $\mathrm{N}$ - blue; $\mathrm{H}$ - white. 

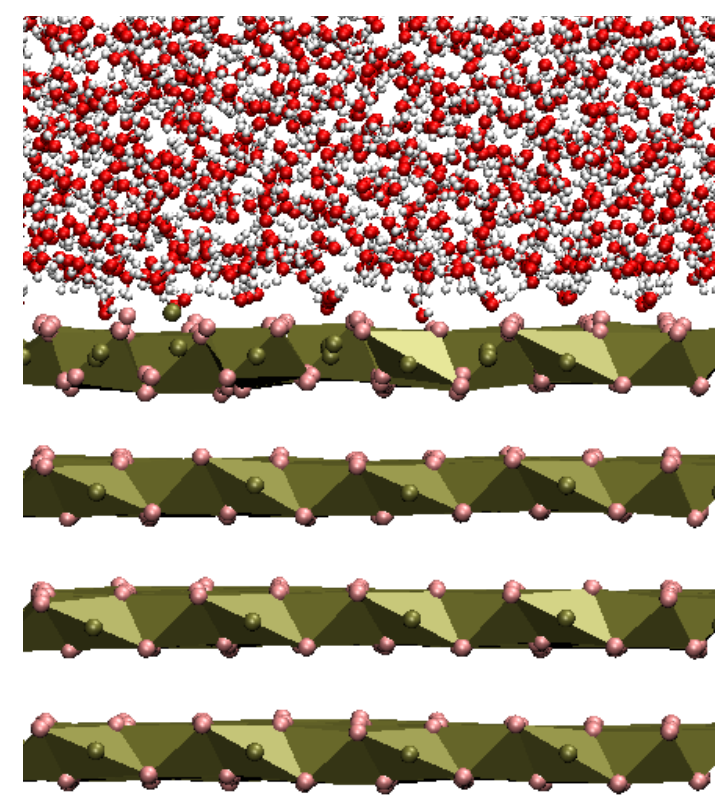

Figure S2. MD simulation snapshot verifying the insolubility of the $\mathrm{PbI}_{2}$ crystal (freely exposed to water for $10 \mathrm{~ns}$ ) in contact with water at $300 \mathrm{~K}$. A pre-equilibrated water box was added on top of the equilibrated $\mathrm{PbI}_{2}$ crystal, after which the atoms in the $\mathrm{PbI}_{2}$ crystal are restrained at their initial positions using springs to allow merging of the $\mathrm{PbI}_{2}$ and the water phase. Such restrains were released before the $10 \mathrm{~ns}$ equilibration run (freely exposed to water) mentioned above. Color code: $\mathrm{Pb}$ - tan; I - pink; $\mathrm{H}$ - white; and $\mathrm{O}$ - red. 
(a)

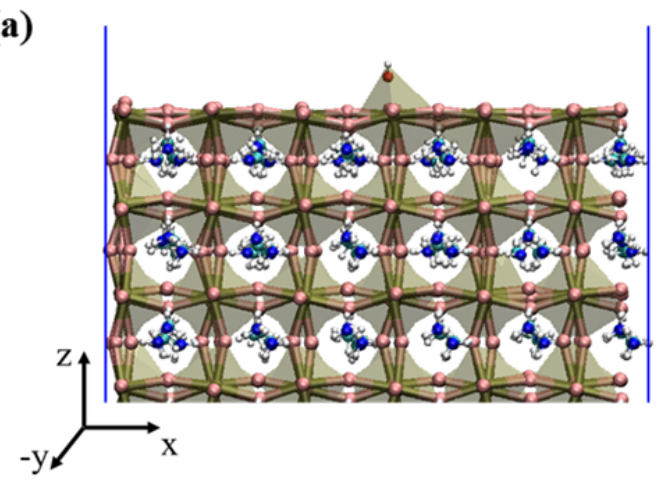

(b)

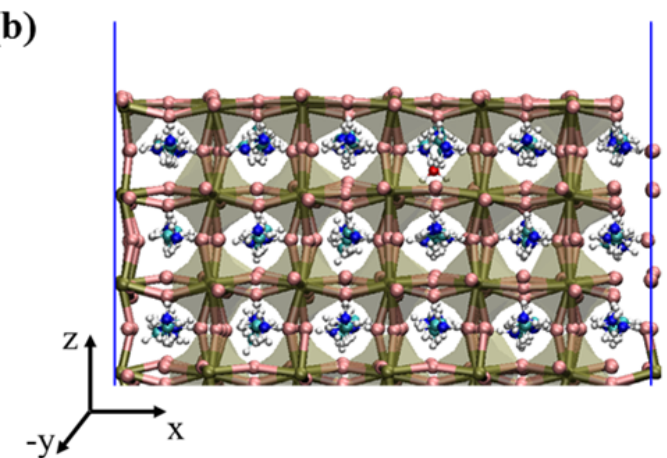

(c)

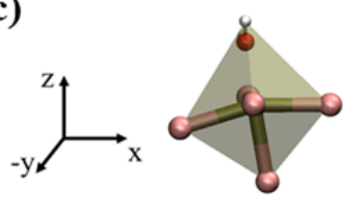

(d)

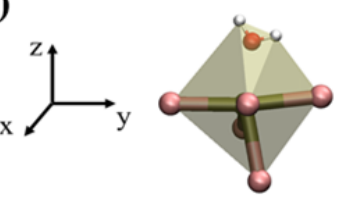

(e)

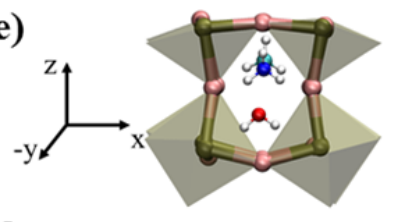

(f)

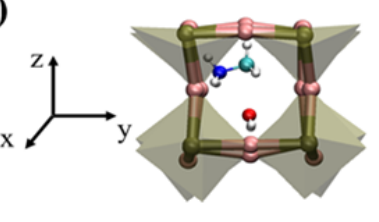

Figure S3. Equilibrated MD simulation snapshots of the near-surface region showing a single water molecule: (a) adsorbed on the $\left[\mathrm{PbI}_{2}\right]^{0}$ surface of a $\mathrm{MAPbI}_{3}$ slab, and (b) infiltrated into the same $\mathrm{MAPbI}_{3}$ slab. (c)-(d) Side views showing the water molecule adsorbed to the nearest $\mathrm{PbI}_{5}^{3-}$ pyramid. (e)-(f) Side views showing the infiltrated water molecule, the nearest $\mathrm{MA}^{+}$cation, and the surrounding $\mathrm{PbI}_{x}$ polyhedra. Color code: $\mathrm{Pb}$ - tan; I - pink; $\mathrm{C}$ - blue; $\mathrm{N}$ - navy; $\mathrm{H}$ - white; and O - red. 


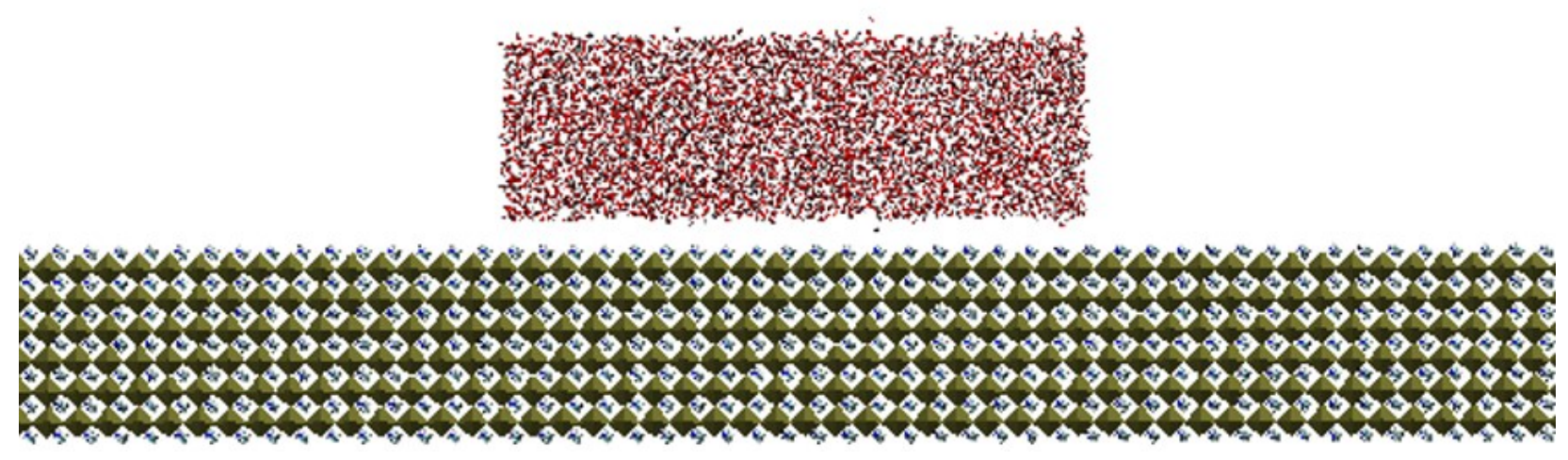

Figure S4. Atomistic configuration of the initial $\mathrm{MAPbI}_{3}$-water contact angle model, in which the $\mathrm{MAPbI}_{3}$ thin film is positioned very close to (separated by a small gap) a liquid water box with 5,500 water molecules and a dimension of $12.00 \times 3.73 \times 3.73 \mathrm{~nm}^{3}$. 


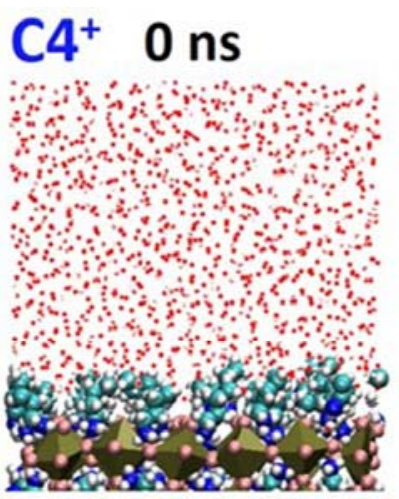

\section{$8 \mathrm{~ns}$}

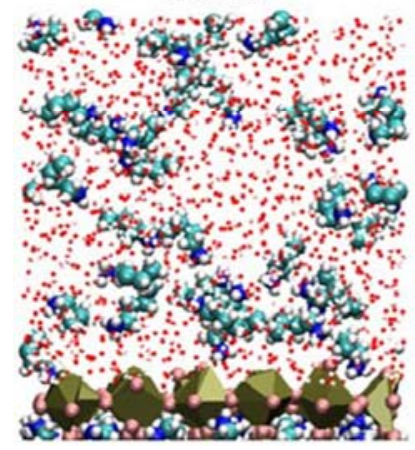

$1.5 \mathrm{~ns}$

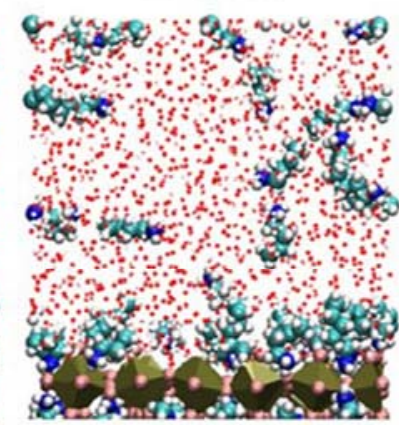

$16 \mathrm{~ns}$

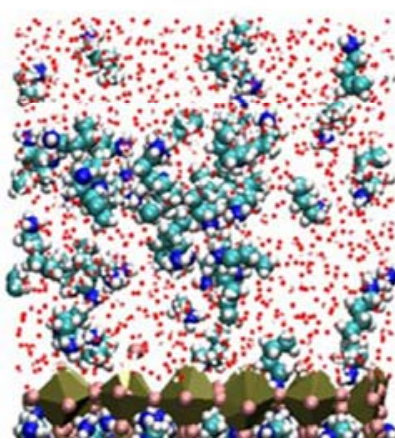

4 ns

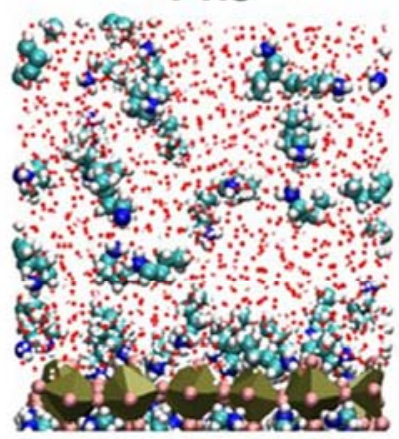

17.5 ns
$5.5 \mathrm{~ns}$

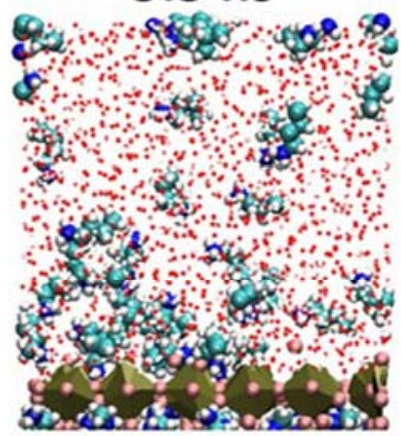

\section{$18.5 \mathrm{~ns}$}

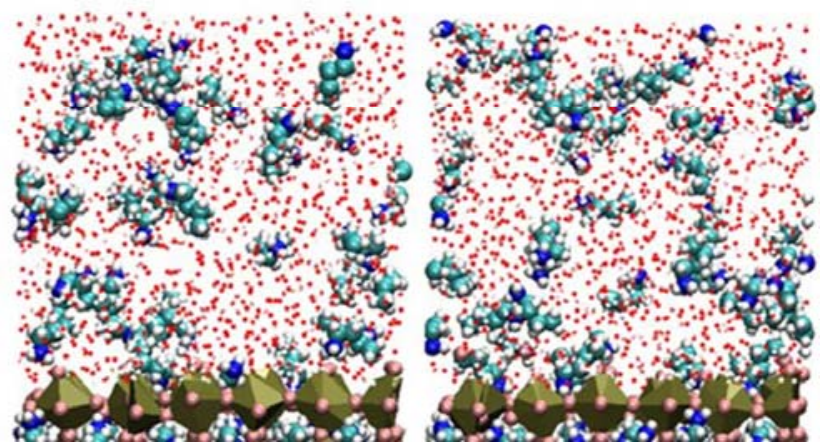

Figure S5. Dissociation and aggregation of $\mathrm{C}^{+}$ligands as a function of simulation time (0 to

$18.5 \mathrm{~ns})$ in water at $800 \mathrm{~K}$. 


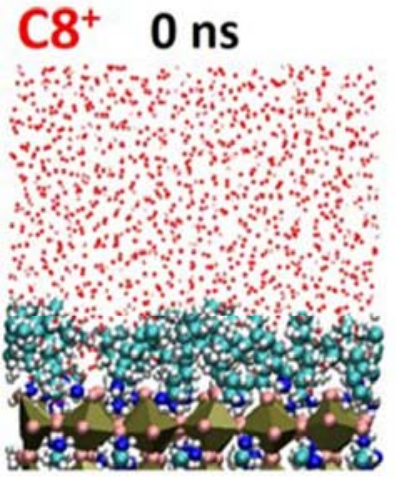

$8 \mathrm{~ns}$

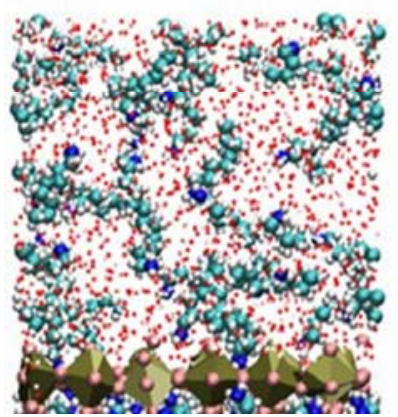

$1 \mathrm{~ns}$

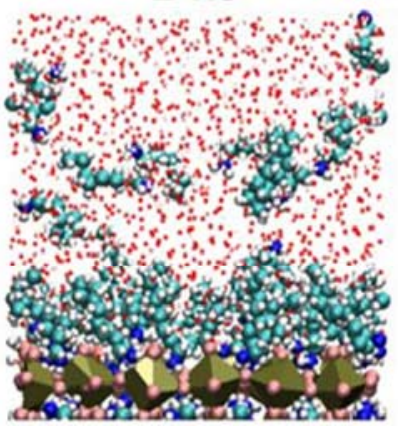

$8.5 \mathrm{~ns}$

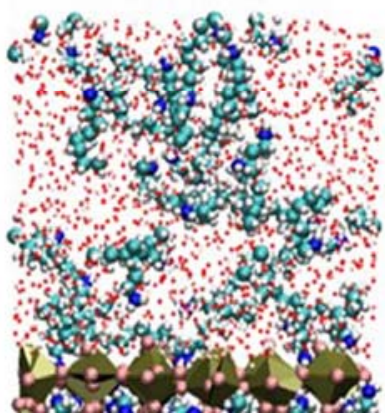

3 ns

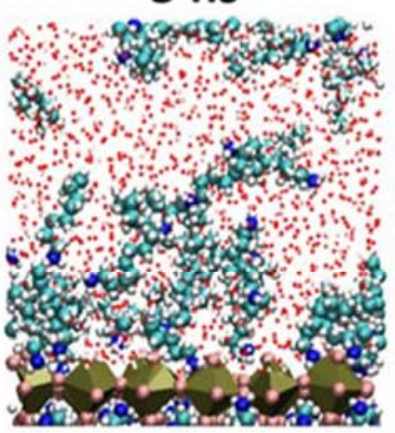

$12 \mathrm{~ns}$

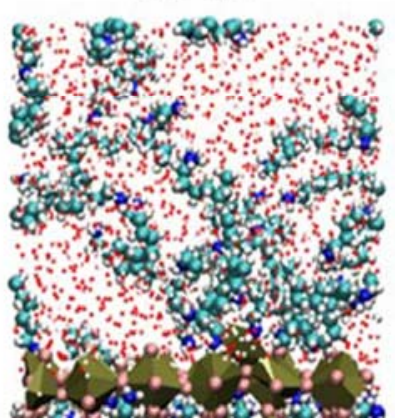

$5.5 \mathrm{~ns}$

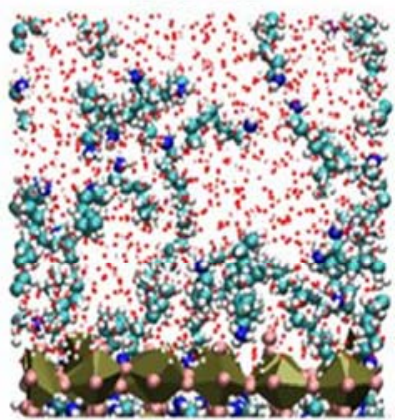

$13.5 \mathrm{~ns}$

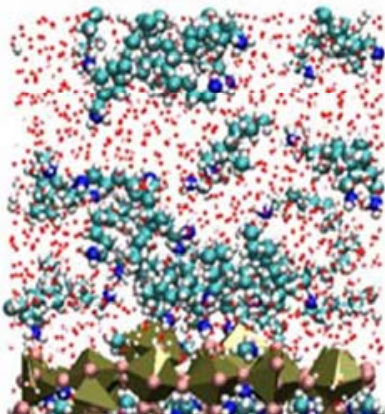

Figure S6. Dissociation and aggregation of $\mathrm{C}^{+}$ligands as a function of simulation time $(0$ to $13.5 \mathrm{~ns})$ in water at $800 \mathrm{~K}$. 

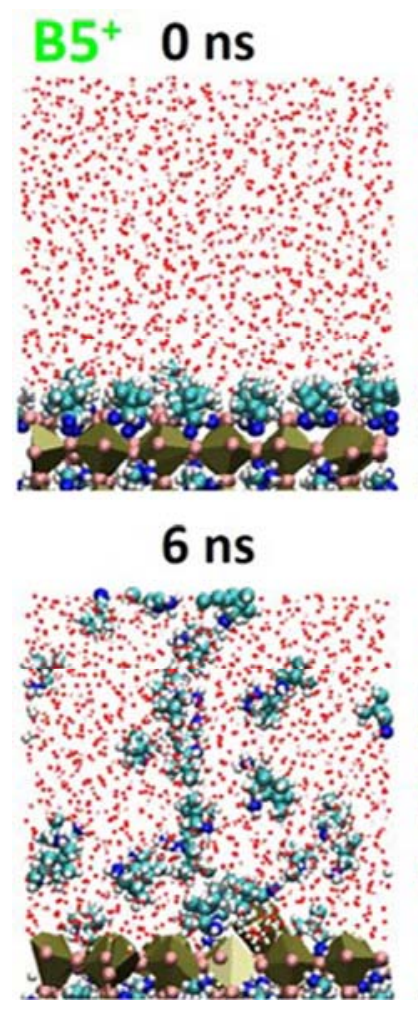

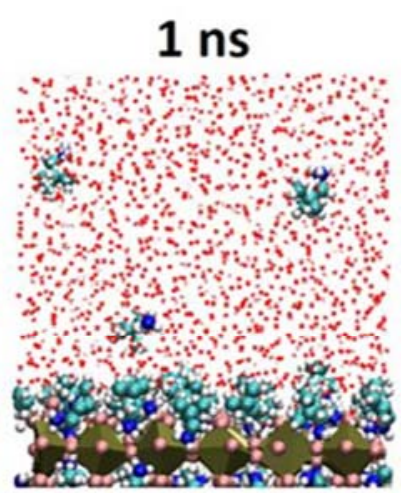

$8 \mathrm{~ns}$

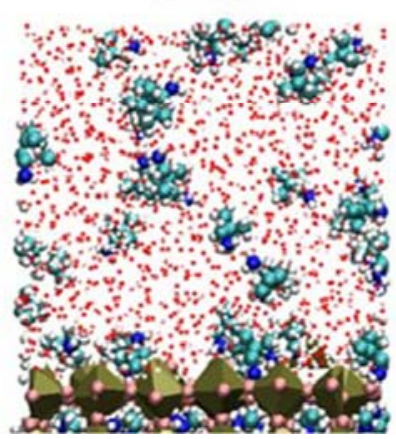

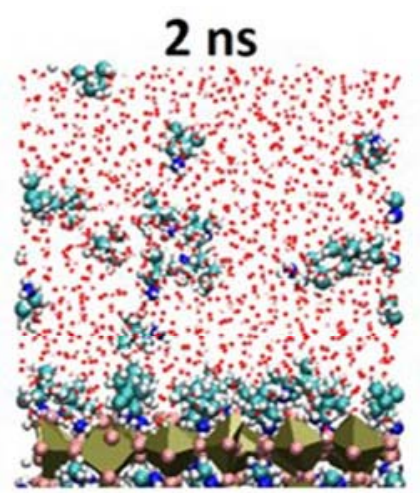

\section{$11.9 \mathrm{~ns}$}

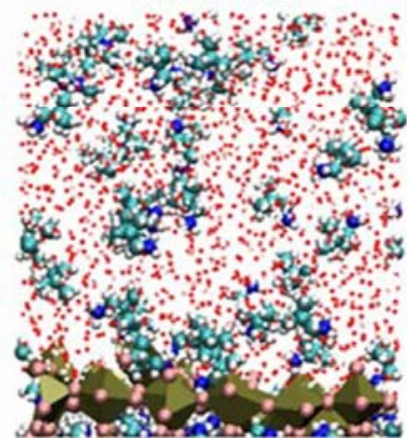

5.5 ns

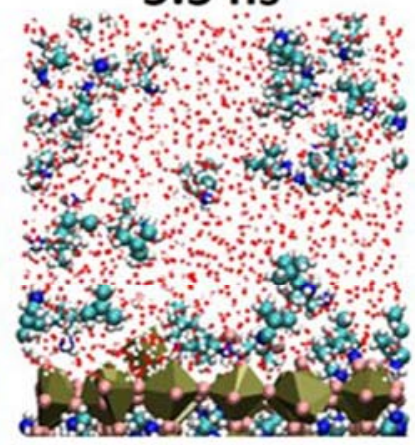

$13.4 \mathrm{~ns}$

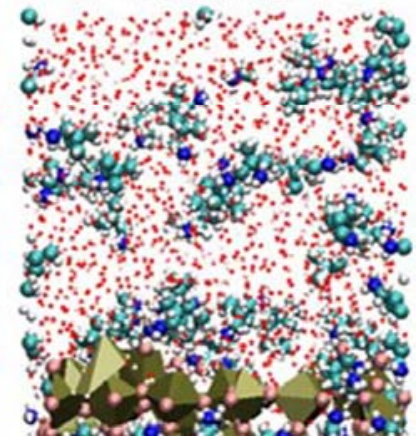

Figure S7. Dissociation and aggregation of $\mathrm{B}^{+}$ligands as a function of simulation time (0 to $13.4 \mathrm{~ns})$ in water at $800 \mathrm{~K}$. 

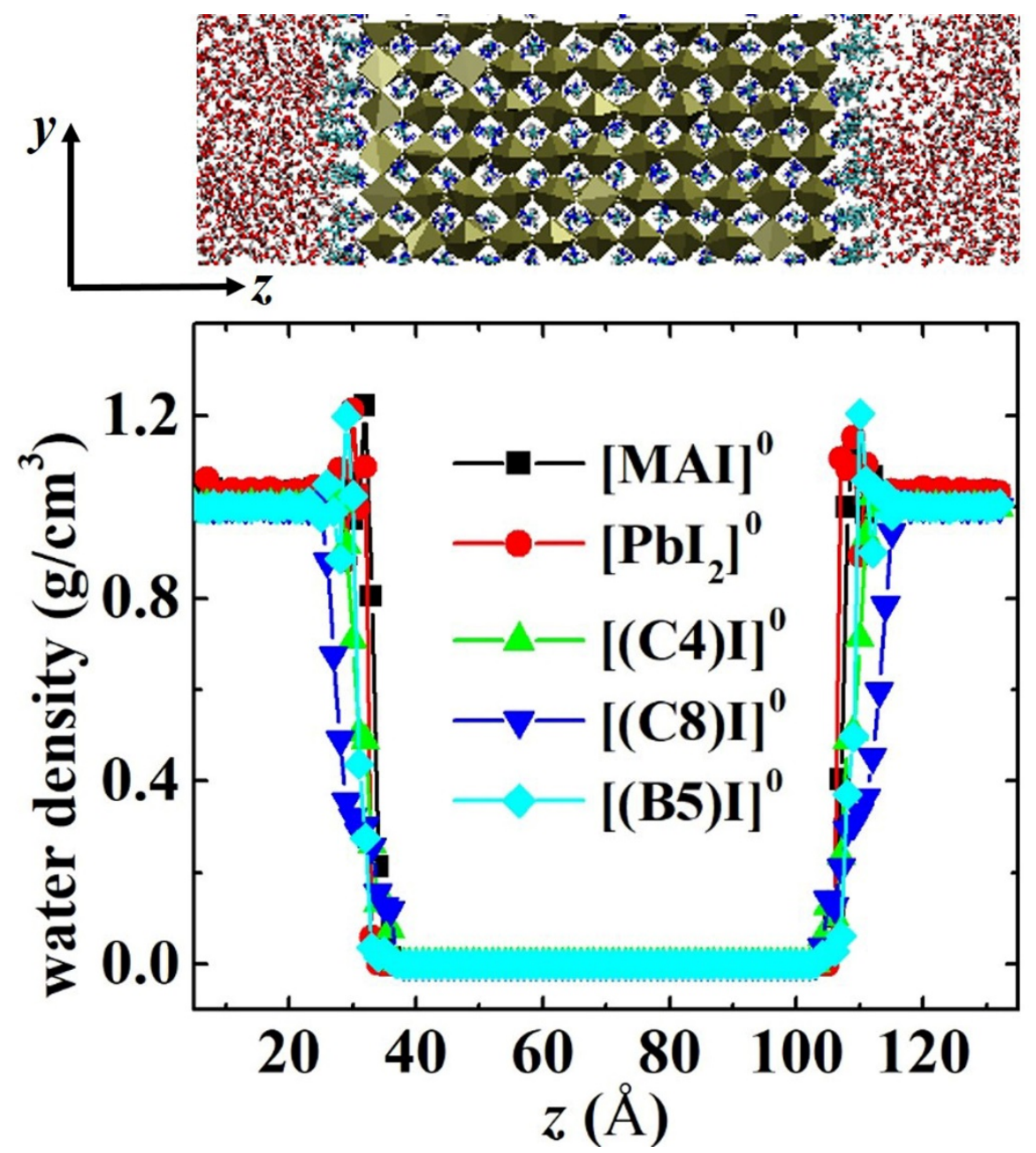

Figure S8. Simulated density profiles of water molecules along the $z$-axis normal to different types of free surfaces in contact with water at $300 \mathrm{~K}$. The top panel illustrates the corresponding atomistic configuration of the simulation model along the $y$-z plane. 


\section{(a) $\left[(\mathrm{C} 4)_{0.5} \mathrm{MA}_{0.5} \mathrm{I}\right]^{0}$}

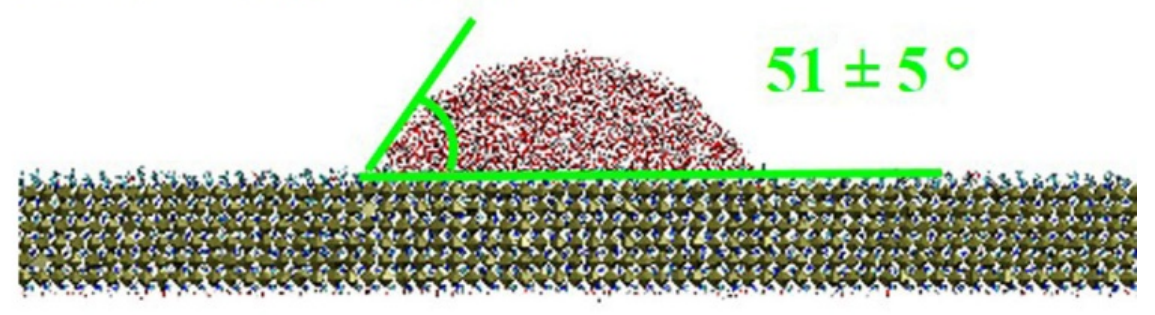

\section{(b) $\left[(\mathrm{C} 8)_{0.5} \mathrm{MA}_{0.5} \mathrm{I}\right]^{0}$}

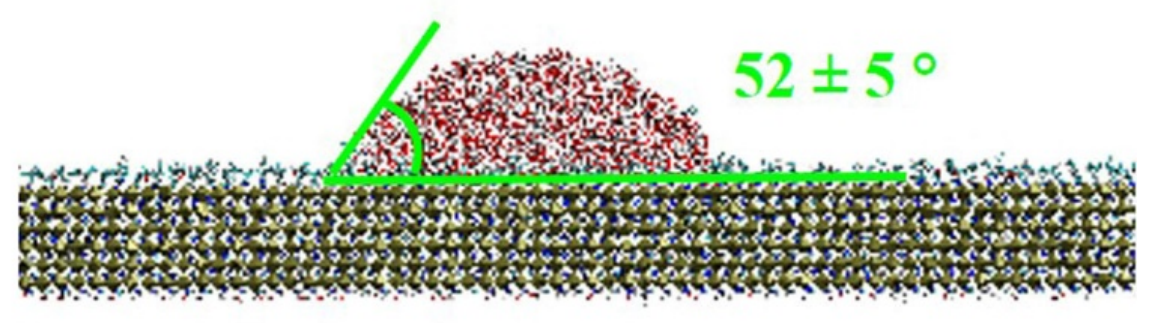

\section{(c) $\left[(\mathrm{B5})_{0.5} \mathbf{M A}_{0.5} \mathrm{I}\right]^{0}$}

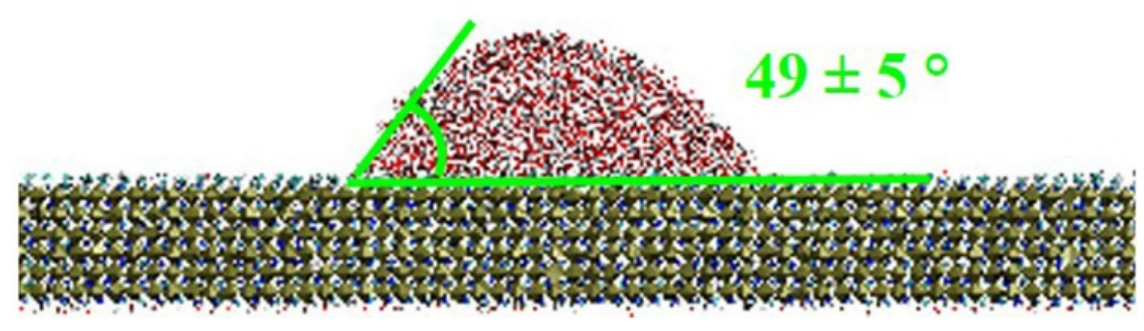

Figure S9. Equilibrium MD simulation snapshots of water droplets on top of different ligandpassivated $\mathrm{MAPbI}_{3}$ surfaces at half surface coverages $\left(\sigma=50 \%\right.$ ), including (a) $\left[(\mathrm{C} 4)_{0.5} \mathrm{MA}_{0.5} \mathrm{I}\right]^{0}$, (b) $\left[(\mathrm{C} 8)_{0.5} \mathrm{MA}_{0.5} \mathrm{I}\right]^{0}$, and (c) $\left[(\mathrm{B} 5)_{0.5} \mathrm{MA}_{0.5} \mathrm{I}\right]^{0}$ surfaces. The values of contact angles for different free surfaces are presented in green. 
Table S1. Pairwise parameters of the m-MYP potential developed here for $\mathrm{MAPbI}_{3}$ and water. ${ }^{\text {(a) }}$

\begin{tabular}{|c|c|c|c|c|c|}
\hline \multicolumn{6}{|c|}{ Non-bonded pairwise interaction: } \\
\hline Atom type $i$ & Atom type $j$ & Pair Style & $A / \mathrm{kcal} \cdot \mathrm{mol}^{-1}$ & $\rho / \AA$ & $\mathrm{C} / \mathrm{kcal} \cdot \AA^{6}$ \\
\hline $\mathrm{Pb}$ & $\mathrm{Pb}$ & Buckingham & 371321.8 & 0.099492 & 25480.4 \\
\hline $\mathrm{Pb}$ & $\mathrm{I}$ & Buckingham & 158835.0 & 0.339893 & 11784.8 \\
\hline I & I & Buckingham & 43145.4 & 0.464671 & 10774.0 \\
\hline $\mathrm{Pb}$ & $\mathrm{N}$ & Buckingham & 12064551.0 & 0.093188 & 0.0 \\
\hline $\mathrm{Pb}$ & $\mathrm{C}$ & Buckingham & 12860.55 & 0.131651 & 0.0 \\
\hline I & $\mathrm{N}$ & Buckingham & 43589.2 & 0.327250 & 0.0 \\
\hline I & $\mathrm{C}$ & Buckingham & 41912.6 & 0.325237 & 0.0 \\
\hline \multicolumn{6}{|c|}{ Non-bonded pairwise interaction: } \\
\hline Atom type $i$ & Atom type $j$ & Pair Style & $\varepsilon / \mathrm{kcal}^{\prime} \cdot \mathrm{mol}^{-1}$ & $\sigma / \AA$ & \\
\hline $\mathrm{Pb}^{(\mathrm{b})}$ & $\mathrm{Pb}^{(\mathrm{b})}$ & LJ & 0.05570 & 3.598300 & \\
\hline $\mathrm{I}^{(\mathrm{b})}$ & $\mathrm{I}^{(\mathrm{b})}$ & $\mathrm{LJ}$ & 0.07000 & 5.400000 & \\
\hline $\mathrm{Pb}$ & $\mathrm{HC}$ & LJ & 0.01287 & 2.831268 & \\
\hline $\mathrm{Pb}$ & $\mathrm{HN}$ & $\mathrm{LJ}$ & 0.03597 & 2.142276 & \\
\hline $\mathrm{I}$ & $\mathrm{HC}$ & $\mathrm{LJ}$ & 0.02945 & 3.605215 & \\
\hline I & $\mathrm{HN}$ & LJ & 0.04238 & 2.446715 & \\
\hline $\mathrm{N}$ & $\mathrm{N}$ & $\mathrm{LJ}$ & 0.17000 & 3.250000 & \\
\hline $\mathrm{N}$ & $\mathrm{HC}$ & LJ & 0.05170 & 2.605000 & \\
\hline $\mathrm{N}$ & $\mathrm{C}$ & $\mathrm{LJ}$ & 0.13640 & 3.324800 & \\
\hline $\mathrm{N}$ & $\mathrm{HN}$ & $\mathrm{LJ}$ & 0.05170 & 2.159500 & \\
\hline $\mathrm{HC}$ & $\mathrm{HC}$ & $\mathrm{LJ}$ & 0.01570 & 1.960000 & \\
\hline $\mathrm{HC}$ & $\mathrm{C}$ & LJ & 0.04140 & 2.679800 & \\
\hline $\mathrm{HC}$ & $\mathrm{HN}$ & $\mathrm{LJ}$ & 0.01570 & 1.514500 & \\
\hline $\mathrm{C}$ & $\mathrm{C}$ & LJ & 0.10940 & 3.399700 & \\
\hline $\mathrm{C}$ & $\mathrm{HN}$ & $\mathrm{LJ}$ & 0.04140 & 2.234400 & \\
\hline $\mathrm{HN}$ & $\mathrm{HN}$ & $\mathrm{LJ}$ & 0.01570 & 1.069100 & \\
\hline $\mathrm{Pb}$ & $\mathrm{O}$ & $\mathrm{LJ}$ & 0.09300 & 3.381940 & \\
\hline I & $\mathrm{O}$ & $\mathrm{LJ}$ & 0.10430 & 4.134500 & \\
\hline $\mathrm{O}$ & $\mathrm{O}$ & $\mathrm{LJ}$ & 0.15540 & 3.165570 & \\
\hline HW & HW & $\mathrm{LJ}$ & 0.00000 & 0.000000 & \\
\hline
\end{tabular}


Atomic Partial Charges:

\begin{tabular}{|c|c|c|c|c|c|}
\hline \hline $\mathrm{Pb}$ & 2.0000 & $\mathrm{I}$ & -1.0000 & $\mathrm{~N}$ & -0.7860 \\
\hline $\mathrm{C}$ & 0.1180 & $\mathrm{HC}$ & 0.1030 & $\mathrm{HN}$ & 0.4530 \\
\hline $\mathrm{O}$ & -0.8476 & $\mathrm{HW}$ & 0.4238 & & \\
\hline \hline
\end{tabular}

(a) $\mathrm{HC}$ represents the $\mathrm{H}$ atom that bonds to $\mathrm{C}$ in $\mathrm{CH}_{3} \mathrm{NH}_{3}{ }^{+}$, $\mathrm{HN}$ represents the $\mathrm{H}$ atom that bonds to $\mathrm{N}$ in $\mathrm{CH}_{3} \mathrm{NH}_{3}{ }^{+}$, and $\mathrm{HW}$ represents the $\mathrm{H}$ atom that bonds to $\mathrm{O}$ in water.

(b) The $\mathrm{LJ}$ parameters for $\mathrm{Pb}-\mathrm{Pb}^{20}$ and $\mathrm{I}-\mathrm{I}^{21}$ pairwise interactions were only used for deriving the cross-term $\mathrm{LJ}$ parameters for $\mathrm{Pb}-\mathrm{O}$ and $\mathrm{I}-\mathrm{O}$ interactions by applying the arithmetic mixing rule. 
Table S2. Comparison between the structure and mechanical properties of pseudo-cubic $\mathrm{MAPbI}_{3}$ calculated using the m-MYP potential developed here and those from DFT calculations. ${ }^{16}$

\begin{tabular}{c|c|c}
\hline & This Study Using m-MYP & DFT Calculations \\
\hline Bulk Modulus from MM $(\mathrm{GPa})$ & 16.44 & $16.4^{16}$ \\
\hline Shear Modulus from MM $(\mathrm{GPa})$ & 8.97 & $8.7^{16}$ \\
\hline Unit Cell Volume from MM $\left(\AA^{3}\right)$ & 250 & $250^{16}$ \\
\hline Young's Modulus from MM $(\mathrm{GPa})$ & 24.9 & $22.2^{16}$ \\
\hline Young's Modulus from MD $(\mathrm{GPa})$ & $20.4(300 \mathrm{~K})$ & $\mathrm{NA}$ \\
\hline \hline
\end{tabular}

Table S3. Comparison between properties involving $\mathrm{MAPbI}_{3}$-water interactions calculated using the m-MYP potential developed here and those from DFT calculations ${ }^{8}$ and experiments. ${ }^{25}$

\begin{tabular}{|c|c|c|c|}
\hline & This Study & DFT Calculations & Experiments $^{(a)}$ \\
\hline Water Adsorption Energy (eV) & 0.80 & $0.71^{8}$ & NA \\
\hline Water Infiltration Energy (eV) & 0.47 & $0.37^{8}$ & NA \\
\hline Water Contact Angle on $\left[\mathrm{PbI}_{2}\right]^{0}$ & $\approx 0^{\circ}$ & NA & \multirow{2}{*}{$44^{\circ 25}$} \\
\hline Water Contact Angle on [MAI] $]^{0}$ & $40 \pm 5^{\circ}$ & NA & \\
\hline
\end{tabular}

(a) The $\mathrm{MAPbI}_{3}$ surface types are not specified or identified in experiments when measuring the water contact angles on $\mathrm{MAPbI}_{3}$.

Table S4. The LJ parameters of water molecules based on the SPC/E model. ${ }^{19}$

\begin{tabular}{cccc}
\hline \hline Pair & $\sigma(\AA)$ & $\boldsymbol{\varepsilon}(\mathrm{kcal} / \mathrm{mol})$ & Charges (e) \\
\hline $\mathrm{O}-\mathrm{O}$ & 3.1656 & 0.1554 & 0.8476 \\
\hline $\mathrm{H}-\mathrm{H}$ & 0.0000 & 0.0000 & 0.4238 \\
\hline \hline
\end{tabular}




\section{References}

(1) Mattoni, A.; Filippetti, A.; Saba, M. I.; Delugas, P. Methylammonium Rotational Dynamics in Lead Halide Perovskite by Classical Molecular Dynamics: The Role of Temperature. J. Phys. Chem. C 2015, 119, 17421-17428.

(2) Yu, J.; Wang, M.; Lin, S. Probing the Soft and Nanoductile Mechanical Nature of Single and Polycrystalline Organic-Inorganic Hybrid Perovskites for Flexible Functional Devices. ACS Nano 2016, 10, 11044-11057.

(3) Wang, M.; Lin, S. Anisotropic and Ultralow Phonon Thermal Transport in OrganicInorganic Hybrid Perovskites: Atomistic Insights into Solar Cell Thermal Management and Thermoelectric Energy Conversion Efficiency. Adv. Funct. Mater. 2016, 26, 5297-5306.

(4) Caddeo, C.; Melis, C.; Saba, M. I.; Filippetti, A.; Colombo, L.; Mattoni, A. Tuning the thermal conductivity of methylammonium lead halide by the molecular substructure. Phys. Chem. Chem. Phys. 2016, 18, 24318-24324.

(5) Delugas, P.; Caddeo, C.; Filippetti, A.; Mattoni, A. Thermally Activated Point Defect Diffusion in Methylammonium Lead Trihalide: Anisotropic and Ultrahigh Mobility of Iodine. $J$. Phys. Chem. Lett. 2016, 7, 2356-2361.

(6) Wang, J.; Zhao, L.; Wang, M.; Lin, S. Molecular Insights into Early Nuclei and Interfacial Mismatch during Vapor Deposition of Hybrid Perovskites on Titanium Dioxide Substrate. Cryst. Growth Des. 2017, 17, 6201-6211.

(7) Liu, S.; Cohen, R. E. Response of Methylammonium Lead Iodide to External Stimuli and Caloric Effects from Molecular Dynamics Simulations. J. Phys. Chem. C 2016, 120, 1727417281.

(8) Caddeo, C.; Saba, M. I.; Meloni, S.; Filippetti, A.; Mattoni, A. Collective Molecular Mechanisms in the CH3NH3PbI3 Dissolution by Liquid Water. ACS Nano 2017, 11, 9183-9190.

(9) Giovambattista, N.; Debenedetti, P. G.; Rossky, P. J. Effect of Surface Polarity on Water Contact Angle and Interfacial Hydration Structure. J. Phys. Chem. B 2007, 111, 9581-9587.

(10) Caddeo, C.; Marongiu, D.; Meloni, S.; Filippetti, A.; Quochi, F.; Saba, M.; Mattoni, A. Hydrophilicity and Water Contact Angle on Methylammonium Lead Iodide. Adv. Mater. Interfaces. 2019, 6, 1801173.

(11) Handley, C. M.; Freeman, C. L. A New Potential for Methylammonium Lead Iodide. Phys. Chem. Chem. Phys. 2017, 19, 2313-2321.

(12) Ponder, J. W.; Case, D. A. Force Fields for Protein Simulations. Adv. Protein Chem. 2003, $66,27-86$.

(13) MacKerell, A. D.; Bashford, D.; Bellott, M.; Dunbrack, R. L.; Evanseck, J. D.; Field, M. J.; Fischer, S.; Gao, J.; Guo, H.; Ha, S. et al. All-Atom Empirical Potential for Molecular Modeling and Dynamics Studies of Proteins. J. Phys. Chem. B 1998, 102, 3586-3616.

(14) Jorgensen, W. L.; Maxwell, D. S.; Tirado-Rives, J. Development and Testing of the OPLS All-Atom Force Field on Conformational Energetics and Properties of Organic Liquids. J. Am. Chem. Soc. 1996, 118, 11225-11236.

(15) Gale, J. D.; Rohl, A. L. The General Utility Lattice Program (GULP). Mol. Simult. 2003, 29, 291-341.

(16) Feng, J. Mechanical properties of hybrid organic-inorganic $\mathrm{CH}_{3} \mathrm{NH}_{3} \mathrm{BX} \mathrm{X}_{3}(\mathrm{~B}=\mathrm{Sn}, \mathrm{Pb} ; \mathrm{X}=$ $\mathrm{Br}, \mathrm{I})$ perovskites for solar cell absorbers. Apl Mater 2014, 2, 081801.

(17) Hill, R. The Elastic Behaviour of a Crystalline Aggregate. P Phys Soc Lond A 1952, 65, 349-355. 
(18) Plimpton, S. Fast Parallel Algorithms for Short-Range Molecular Dynamics. J. Comput. Phys. 1995, 117, 1-19.

(19) Berendsen, H. J. C.; Grigera, J. R.; Straatsma, T. P. The Missing Term in Effective Pair Potentials. J. Phys. Chem. 1987, 91, 6269-6271.

(20) Li, P.; Roberts, B. P.; Chakravorty, D. K.; Merz, K. M. Rational Design of Particle Mesh Ewald Compatible Lennard-Jones Parameters for +2 Metal Cations in Explicit Solvent. J. Chem. Theory Comput. 2013, 9, 2733-2748.

(21) McDonald, N. A.; Duffy, E. M.; Jorgensen, W. L. Monte Carlo Investigations of Selective Anion Complexation by a Bis(phenylurea) p-tert-Butylcalix[4]arene. J. Am. Chem. Soc. 1998, $120,5104-5111$.

(22) Frisch, M. J.; Trucks, G. W.; Schlegel, H. B.; Scuseria, G. E.; Robb, M. A.; Cheeseman, J. R.; Scalmani, G.; Barone, V.; Petersson, G. A.; Nakatsuji, H. et al. Gaussian 16 Rev. C.01, Wallingford, CT, 2016.

(23) Hockney, R. W.; Eastwood, J. W. Computer Simulation Using Particles. crc Press: 1988.

(24) Mosconi, E.; Azpiroz, J. M.; De Angelis, F. Ab Initio Molecular Dynamics Simulations of Methylammonium Lead Iodide Perovskite Degradation by Water. Chem Mater 2015, 27, 48854892.

(25) Yang, S.; Wang, Y.; Liu, P.; Cheng, Y.-B.; Zhao, H. J.; Yang, H. G. Functionalization of Perovskite Thin Films with Moisture-Tolerant Molecules. Nat. Energy 2016, 1, 15016. 